AUSTRALIAN JOURNAL OF BASIC AND
ASSN:1991-8178
EISSN: $2309-8414$
DOI: $10.22587 /$ ajbas.2017.11.13.5
Journal home page: www.ajbasweb.com

\title{
Representation of The Masonry Walls Techniques By Using FEM
}

\author{
${ }^{1}$ Ali . Laftah. Abbas and ${ }^{2}$ Maan. H. Saeed \\ ${ }^{1}$ Ali .Laftah. Abbas, Assist Prof, University diyala, civil engineering, diyala, Iraq. \\ ${ }^{2}$ Maan. H. Saeed, MSc student, University diyala, civil engineering, diyala, Iraq.
}

\section{Address For Correspondence:}

Maan. H. Saeed, MSc student, diyala of University, civil, engineering, diyala. Iraq. Phone (+00964776287179); E-mail: dyalatophousing@yahoo.com

\section{ART I CLE INFO}

\section{Article history:}

Received 19 August 2017

Accepted 1 November 2017

Available online 11 November 2017

Keywords:

Masonry wall

Keyword finite element modeling

Keyword nonlinear material

\begin{abstract}
A B S T R A C T
Masonry is one of the oldest building systems used to date, although with the development of building construction methods the principle of linking two materials (bricks and mortar) still is the basis. This system has several advantages, including acceptable appearance, strength, durability, thermal insulation and fire resistance, as well as the ease and speed of implementation. Despite these features, this system of construction remains designed to withstand vertical loads and is sensitive to seismic loads. The seismic performance is assessed by calculating the base shear, drift and comparing it with the standard seismic demand requirements. The main objective of this paper evaluates masonry wall modeling using the representation techniques adopted in literature and use the appropriate technique to represent masonry room by using the ABAQUS software under the seismic load. Results: The results of the numerical analysis using the finite element method with the experimental results of the masonry wall, where a significant convergence was achieved. The total displacement value was $15 \mathrm{~mm}$ for the experimental work, while the total displacement value was for micro modeling method 14.32, simplified modeling 14.25 and macro modeling 14.18. As well the results of the macro modeling of room under dynamic load, the maximum displacement found from finite element analysis is $55.51 \mathrm{~mm}$, while the maximum displacement found in the experimental investigation is $60.80 \mathrm{~mm}$. The results showed a great convergence between the techniques of representation. The macro modeling is selected to the representation of the large models as it saves time and effort. As for the analysis of the results, the results were satisfactory under dynamic load. The results were close to the experimental work and proved the efficiency of the ABAQUS program and the suitability of the elements of the program to represent the masonry, rebar and nonlinear properties of the materials.
\end{abstract}

\section{INTRODUCTION}

Masonry is often responsible for carrying vertical forces but their exposure to lateral loads such as winds and earthquakes adds a great responsibility to the masonry construction. Lateral loads with vertical loads lead to tension and shear with pressure inside the wall often resulting in cracks and crashing to the wall parts and splitting to the mortar joints and failure of pressure in the toe of the wall (Costa, A. 2007).

There is a need to provide a design for the building that resists lateral loads such as earthquakes, the wind, explosion and needs to know the internal forces. Therefore, it is necessary to estimate the masonry building behavior of the lateral loads by simulating the masonry building behavior of the external lateral load to expected damage and the validity of the structural. It, therefore, requires the built of an analytical model to evaluate the masonry building and give the researchers a perception of the behavior of it (Aldemir, A. 2010).

There are many techniques to represent the masonry wall, micro modelling, simplified micro modelling, and macro modelling. For the purpose of finding the appropriate technique for modelling large models, these techniques are used to represent a masonry wall and compare the results of maximum displacement and ultimate

Open Access Journal

Published BY AENSI Publication

(C) 2017 AENSI Publisher All rights reserved

This work is licensed under the Creative Commons Attribution International License (CC BY).

http://creativecommons.org/licenses/by/4.0/

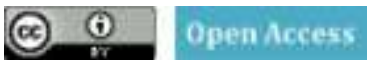

To Cite This Article: 1Ali . Laftah. Abbas and 2Maan. H. Saeed., Representation of The Masonry Walls Techniques By Using FEM. Aust. J. Basic \& Appl. Sci., 11(13): 39-48, 2017 
load between the three techniques. Nonlinear Dynamic procedure (NDP) analysis is the most accurate method to evaluate the response of structures subjected to a ground motion. Where takes into account the variation of the properties of the model during the time (Chambers and Kelly,2004).

The main objective of this paper is to simulate and nonlinear analysis for the masonry walls conducted by using finite element method of the ABAQUS software. To verify the correct representation after comparing the results nonlinear analysis of the experimental the results and use the best way of modeling for the large models.

\section{Methodology:}

The methodology includes wall modeling using three techniques, micro, simplified and macro modeling depending on finite element method of the ABAQUS software. The nonlinear analysis depending on nonlinearity of masonry material represented using the concrete damage plasticity (CDP) model.

\subsection{Modeling techniques for masonry wall:}

Due to the complexity of the masonry construction, because it is consists of several differentiated materials, its study requires the adoption of effective representation techniques. Therefore, Researchers presented several techniques for the purpose of simulating the construction wall, there are three techniques that can be applied in the specific elements method, namely, macro modeling, simplified modeling, and micro modeling as shown in figure (1) (Lourenço, P. J. B. B. 1997).

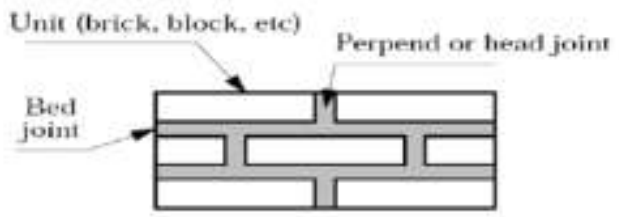

(a)

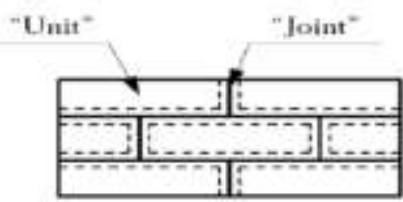

(c)

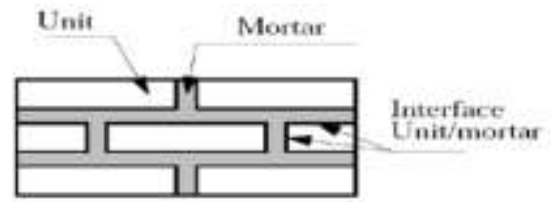

(b)

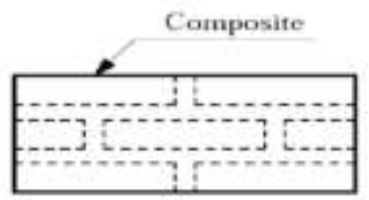

(ci)

Fig. 1: Modeling of masonry wall: (a) masonry sample, (b) micro- modeling, (c) simplified -modeling, (d) macro-modeling(Lourenço, P. J. B. B. 1997).

1- Micro-modeling: It means complex modeling where both the blocks and the joint of mortar are represented by a separate element with an interface element for the purpose of linking the two elements together. This modeling is often used for small models because of the complexity of the details and the need for more variables than the other types as well as taking a lot of time for representation and analysis, but gives more accurate and reliable results and used when the need to study cracks and failures and stresses as shown in Figure (1-b) (Ahmad, S el al., 2014).

2- Simplified micro-modeling: In this approach, brick is modeled was by continuum is element, but is the mortar joint and its interface is with brick is modeled is together in an it interface elements. however in this instance the mortar is not defined as a solid element but rather as an interface between the solid brick elements. These interface element represent the preferential crack locations where shear and tensile cracking occurs (Lourenço, P. J. B. B.,1997). as shown in Figure ( 1c).

3- Macro modeling: This type of modeling is the most common and especially in large models, where both the bricks and the mortar are modeled for one piece that possesses part of the properties of the bricks and the mortar in one. The material properties are introduced through mathematical equations whose variables are the compressive strength of both materials found by researchers or Through the experimental test of brick and mortar samples. This technique is used when there is a need to reduce the time of analysis or the breakdown of storage memory and large size model (Lourenço, P. J. B. B.,1997). as shown in Figure (1d).

\subsection{Finite element modeling of masonry wall and reinforcement concrete in ABAQUS software:}

The ABAQUS software is a set of programming tools and commands used to build and analyze models depending on the finite element method. The ABAQUS software contains a large library of elements that enable the user to represent models in various disciplines as well as represent the linear, nonlinear, static, dynamic, heat transfer, fluid flow, and electromagnetic analysis, so it is a general and comprehensive program of all specialties used throughout the world (Abaqus Manual, 2009). 
Masonry, concrete, and steel are Materials used to represent the physical properties of the model. A set of properties that need to be defined as inputs such as density, modulus of elasticity and plastic properties to represent masonry, concrete, and steel. The materials in this study represented by using brick element C3D8R for masonry, brick, mortar, and concrete, while the truss element T3D2 using to represent the steel. The concrete damage plasticity (CDP) using to represent the nonlinear behavior of the material, its model has the ability to generate nonlinear properties of brittle materials such as concrete. concrete and masonry are a brittle material with very low tensile strength. Therefore, The concrete damage plasticity (CDP) model used to generate nonlinear properties of concrete and masonry (Daniel and Dubey, 2014)

\section{Concrete damage plasticity:}

Masonry, concrete and steel are materials used to represent the physical properties of the model. A set of properties that need to be defined as inputs such as density, modulus of elasticity and plastic properties to represent masonry ,concrete and steel. The concrete damage plasticity (CDP) model has the ability to generate nonlinear properties of brittle materials such as concrete. concrete and masonry are a brittle material with very low tensile strength. Therefore, The concrete damage plasticity (CDP) model used to generate nonlinear properties of concrete and masonry as shown in figure (2) (Daniel and Dubey, 2014), (Bolhassani el at.,2015)
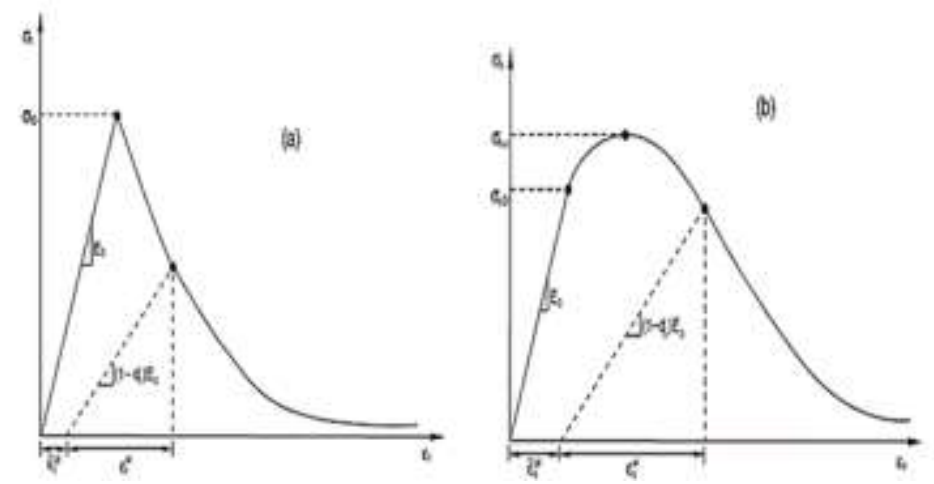

Fig. 2: Concrete damage plasticity (CDP) behavior(a)tension, (b)compression

\section{Brick element ( C3D8R):}

The three-dimensional C3D8R brick reduced integration element is used to represent masonry walls, reinforced concrete slab, brick and mortar in the models. This element has the capability of representing large deformation, geometric and crashing in compressive and cracking in tension. It is defined by 8 nodes, each node has three translational degrees of freedom X, Y, and Z directions as showed in figure (3a). The name of each element in ABAQUS identifies its main aspects. $\mathrm{C}$ means continuum element, 3D means three-dimensional element, 8 Indicates the number of nodes required to create the element and $\mathrm{R}$ reduced integration (Daniel and Dubey, 2014)

\section{Truss element (T3D2):}

When loading of the slender member on the center line or along it, we select the truss element (T3D2) that supports this type of loading for 3D or 2D modeling as shown in figure (3b). The truss element (T3D2) two nodded in this study is used to represent the reinforcing steel of the roof, slab, and lintels (Daniel and Dubey, 2014)

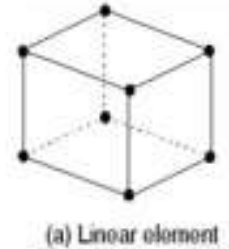

(8-node brick, C3D8)

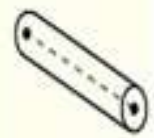

Truss

elements

Fig. 3: a) C3D8R brick element \& b) T3D2 truss element 


\section{Constraints \& Interface:}

many types of connection In order to be able to properly describe the contact between bodies (FE meshes).For each case, a privacy connection should be taken into consideration. Tie constraint is used to connect different model parts with the same material properties. Embedded for the purpose of the representation of the concrete reinforced by the ABAQUS program requires the representation of submerging the reinforcing steel inside the concrete and defining the connection between them. Interface elements there are two ways to represent Interface elements in the ABAQUS The first representation of the Interface elements as shell elements and the second representation as a way of product linking between the solid units, In both cases we need a set of parameters as tangential behavior, normal behavior, cohesive behavior and damage criterion (Abaqus Manual, 2009).

\section{Simulation of modeling techniques for masonry wall by using ABAQUS software:}

The micro, simplified micro and macro modeling strategy are validated next by comparison with experimental results available in the literature. The experimental model of in- plane loaded central opening masonry wall as well-documented results by Vermelfoort and Raijmakers (1992 \& 1993) (Lourenço, 1997) (Aref and Dolatshahi ,2013) is considered. The Figure (4) depicted the details and dimension of masonry wall were made of clay bricks $(210 \mathrm{~mm}, 52 \mathrm{~mm}, 100 \mathrm{~mm})$, the dimension of the wall $(1000 \mathrm{~mm} * 990 \mathrm{~mm})$ consists of 16 rows of bricks and the thickness of the mortar is $10 \mathrm{~mm}$. The wall clamped by two steel stiff beams of top and bottom at horizontal boundaries of the test setup. This testing procedure has been shown in Figure (5) The first step (a) applies the pressure load of $0.3 \mathrm{~N} / \mathrm{mm} 2$ onto the top of the wall. The top of the wall is then constrained in the vertical and out of plane direction in step (b). In step (c), the lateral load $47 \mathrm{kN}$ is applied to the top side of the wall (Lourenço, 1997)

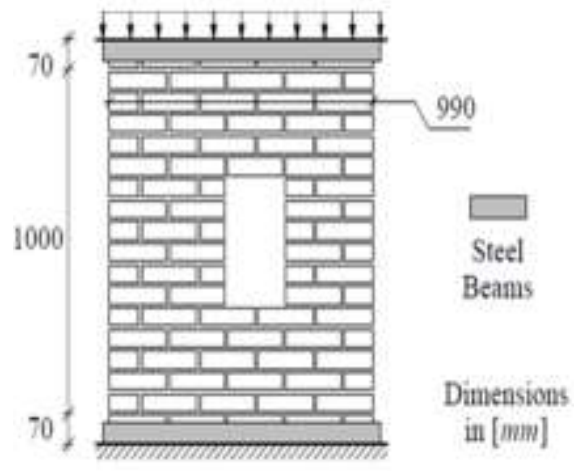

Fig. 4: The dimension of masonry wall with a central opening [2]

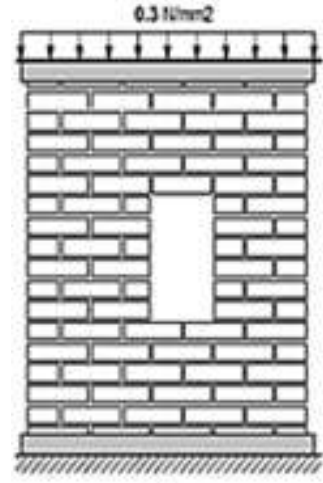

a

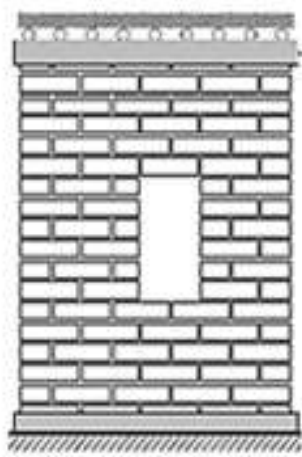

b

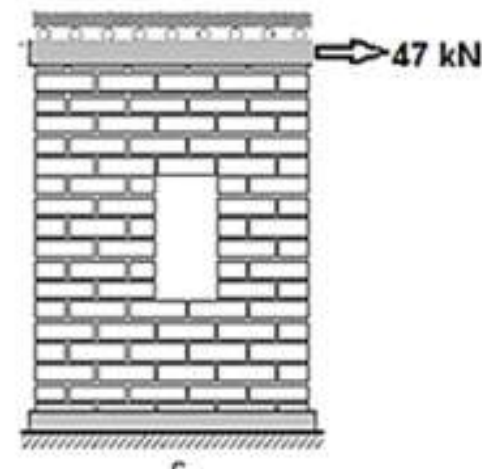

C

Fig. 5: Testing procedure of masonry wall (a) applies the pressure load of $0.3 \mathrm{~N} / \mathrm{mm} 2$ onto the top of the wall (b) The top of the wall is then constrained in the vertical and out of plane (c) the lateral load $47 \mathrm{kN}$ is applied to the top side of the wall (Aldemir, A.,2010).

In the micro modeling, brick and the joint mortar shall be modeled as separate members.The solid brick and cement mortar joints are modeled as a continuum element and it interfaces so between the brick and mortar is or modeled by an interface element.In simplified micro modeling approach, brick is modeled was by continuum element but is the mortar joint and its interface with brick is modeled together in it interface elements. The macro modeling of the masonry wall, modeling of the brick and mortar are a single homogeneous material as shown in Figure (6).The material properties for micro-modeling, simplified-modeling, and macro- modeling are shown in Tables 1 (Annecchiarico el at., 2010). 

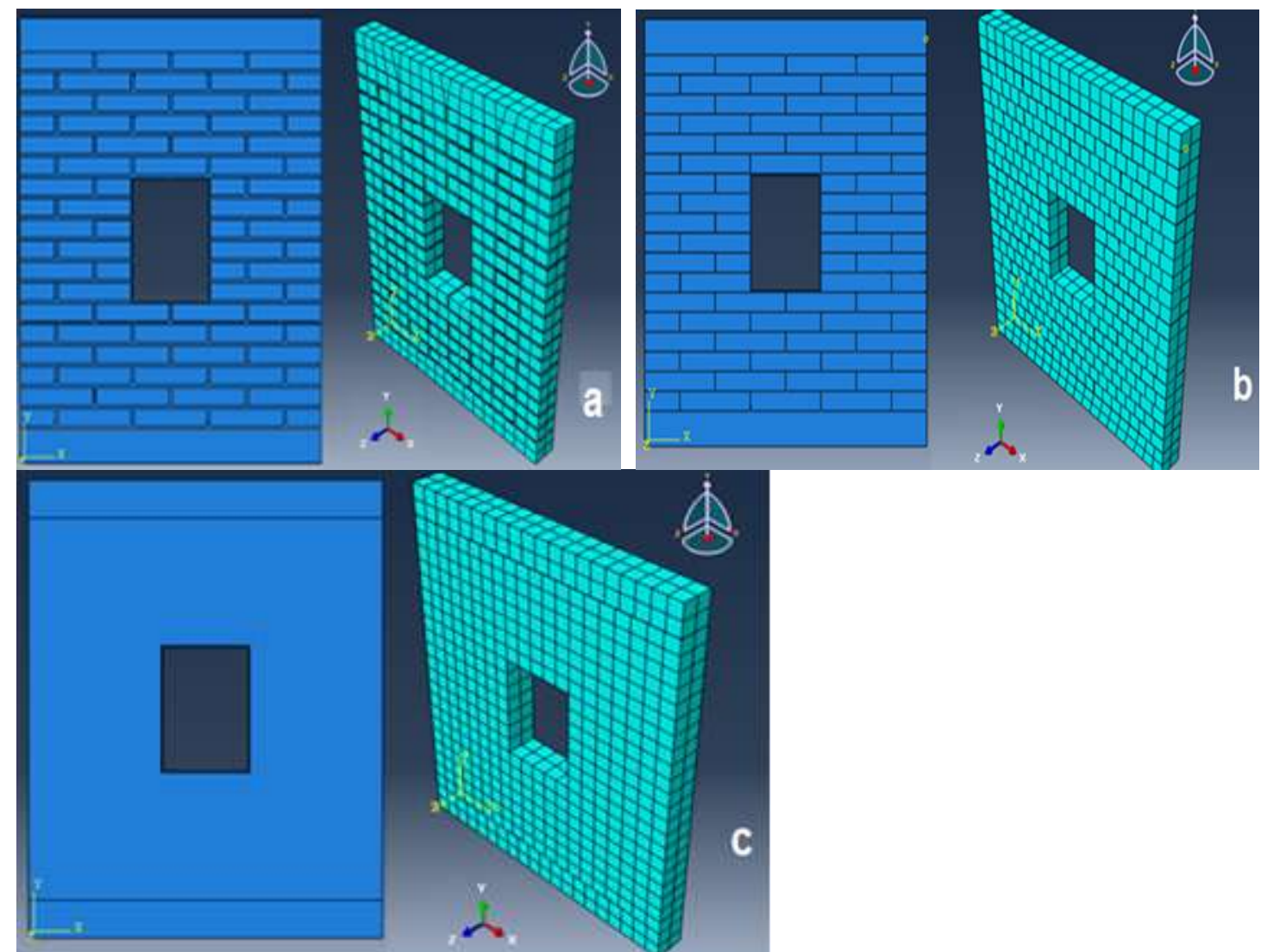

Fig. 6: Finite element modeling for masonry wall and mesh a)micro b)simplified micro c)macro

Table 1: properties of masonry wall

\begin{tabular}{|l|l|l|l|l|l|l|l|}
\hline Micro modeling & $E_{\text {Mpa }}$ & $v$ & $\gamma$ & $f_{c}$ & $f_{\text {Mpa }}$ & GFI Mpa & $\psi$ \\
\hline Brick & 9000 & 0.15 & 2100 & 63 & 2.8 & 0.5 & 30 \\
\hline Mortar & 1000 & 0.22 & 2350 & 4 & 0.5 & 0.125 & 1 \\
\hline Simplified micro modeling & 9000 & 0.15 & 2100 & 63 & 2.8 & 0.5 & 30 \\
\hline Brick & 0.18 & 2100 & 7 & 0.35 & 0.1 & 20 \\
\hline Macro modeling \\
\hline masonry
\end{tabular}

\section{Simulation of masonry room under the seismic load:}

In this experimental case previously presented by (Srisanthi el at., 2014) the main objective of the study to investigate the seismic behavior of masonry building. the study investigated the behavior of single room building models construction from the brick unit under various seismic load. the dimension models $4 \mathrm{~m}$ length, $4 \mathrm{~m}$ width and height $3 \mathrm{~m}$, it construction with scale1:3 of the 3D single room as shown in Figure (7). the model's bricks size $76 \mathrm{~mm} \times 36 \mathrm{~mm} \times 25 \mathrm{~mm}$ with the compressive strength of masonry fm $=5.68 \mathrm{Mpa}$ and Cement mortar ratio is 1:6. The model was tested under dynamic load condition by shake table, The frequency achieved was in the range $0 \mathrm{~Hz}$ to $3 \mathrm{~Hz}$ and the maximum acceleration imposed is $0.5920 \mathrm{~g}$ as shown in Figure (7). 


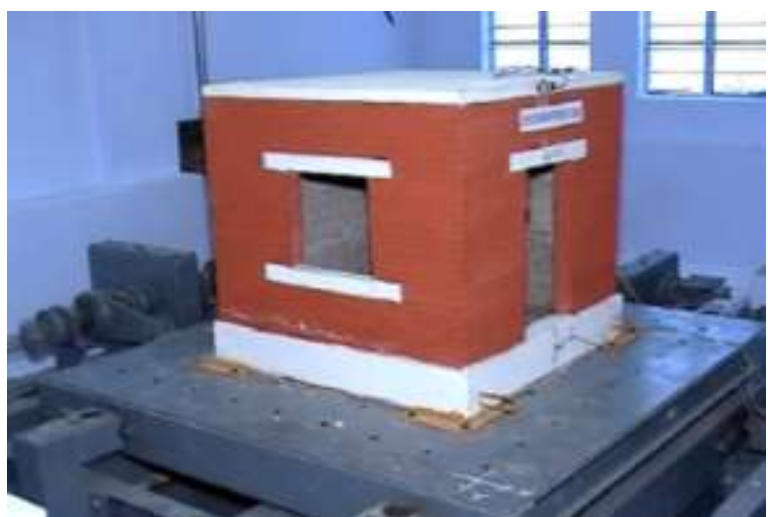

Fig. 7: single room model and shake table

In the single room, it's modeled by using the macro modeling technic being suitable for modeling large models Because of shortened time and effort.The composite materials consist of two different constituent materials(brick, mortar). The material properties for macro- modeling are shown in Tables (2). The finite element modeling dependent ABAQUS 6.13 program by using the macro modeling technic of the masonry room, modeling of the brick and mortar as single homogeneous material shown in Figure (8). The masonry walls, reinforced concrete slab, and reinforced concrete lintel using the brick element C3D8 and reinforcing steel element T3D2.The number of element 3447 and the number of nods 5168 in the model while the weight of the model is 30.7828 tons. The masonry room is analysis for the seismic load includes of the dead and live load.The masonry room is subjected to PGA $(0.592 \mathrm{~g})$ as input ground motion to determine its seismic performance.

Table 2: properties of masonry room

\begin{tabular}{|c|c|c|c|c|c|c|c|}
\hline \multicolumn{8}{|c|}{ macro modeling } \\
\hline Material & $E_{\mathrm{Mpa}}$ & $v$ & $\gamma$ & $f_{C}$ & $f_{t}$ & $\mathrm{Mpa}^{\mathrm{GFI}}$ & $\psi$ \\
\hline masonry & 2500 & 0.2 & 2100 & 5.68 & 0.121 & 0.1 & 20 \\
\hline
\end{tabular}
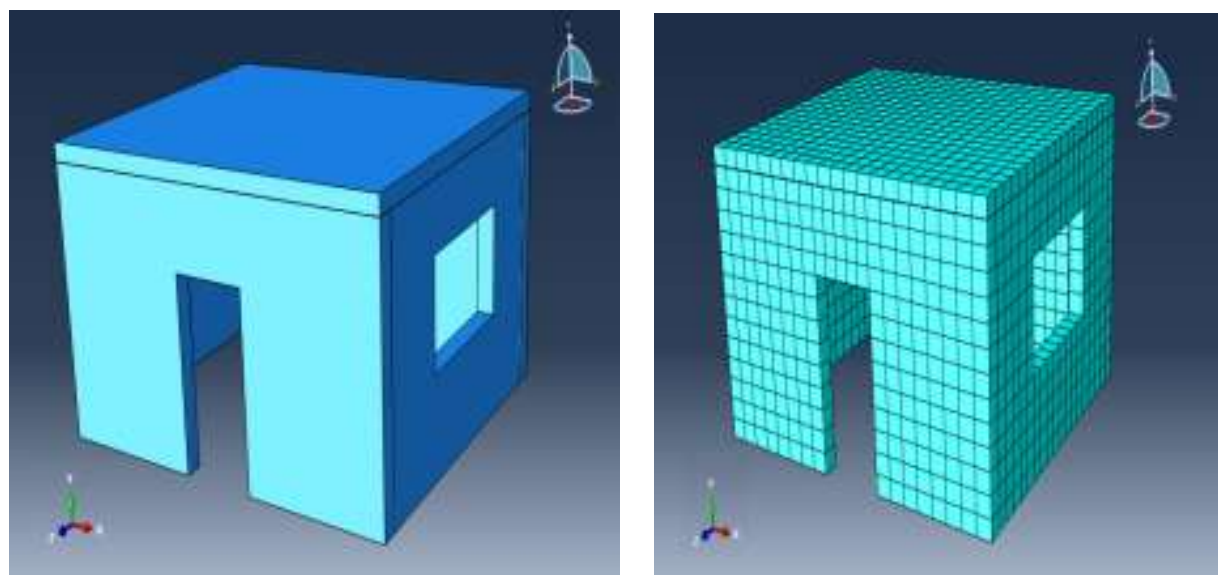

Fig. 8: the finite element modeling by using the macro modeling technic of the masonry room

\section{Results:}

\subsection{Results of masonry wall:}

The deformed shape in figures (9) (10) (11) then applied lateral force $47 \mathrm{kn}$ shows that the three strategies are a great convergence between these representation systems where the displacement of the micro $14.32 \mathrm{~mm}$, the Simplified micro $14.25 \mathrm{~mm}$ and the macro $14.18 \mathrm{~mm}$, while the maximum displacement found in the experimental investigation is $15 \mathrm{~mm}$. Therefore The percentage error representation in the three systems is $4.53 \%$ for micro, $5 \%$ for Simplified and $5.46 \%$ for macro. The curve of load-displacement obtained from the finite element as well as the previous experimental and numerical results of masonry wall are shown in Figure $(12,13,14)$. On other hands when applied control displacement $15 \mathrm{~mm}$ the maximum lateral load in the adopted finite element model is equal to $(46.1 \mathrm{KN})$ for micro modeling, $(45.6 \mathrm{kn})$ for simplified micro modeling and $(45.2$ $\mathrm{kn}$ ) for macro modeling, while The maximum lateral load found in the experimental investigation is equal to 47 $\mathrm{kN}$. Therefore The percentage error representation in the three systems is $2 \%$ for micro ,3\% for Simplified and 
4\% for macro. The analysis results exhibit a good agreement of finite element analysis with previous experimental and numerical results for which amount of error is logical and acceptable.

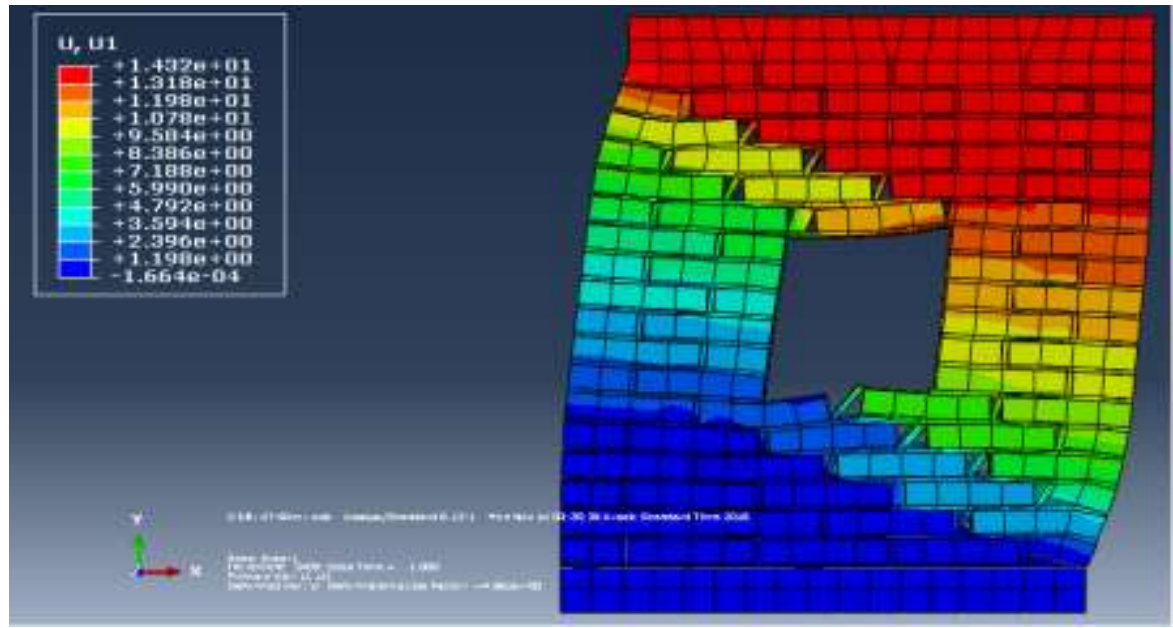

Fig. 9: Finite element modeling of Micro-modeling by using ABAQUS

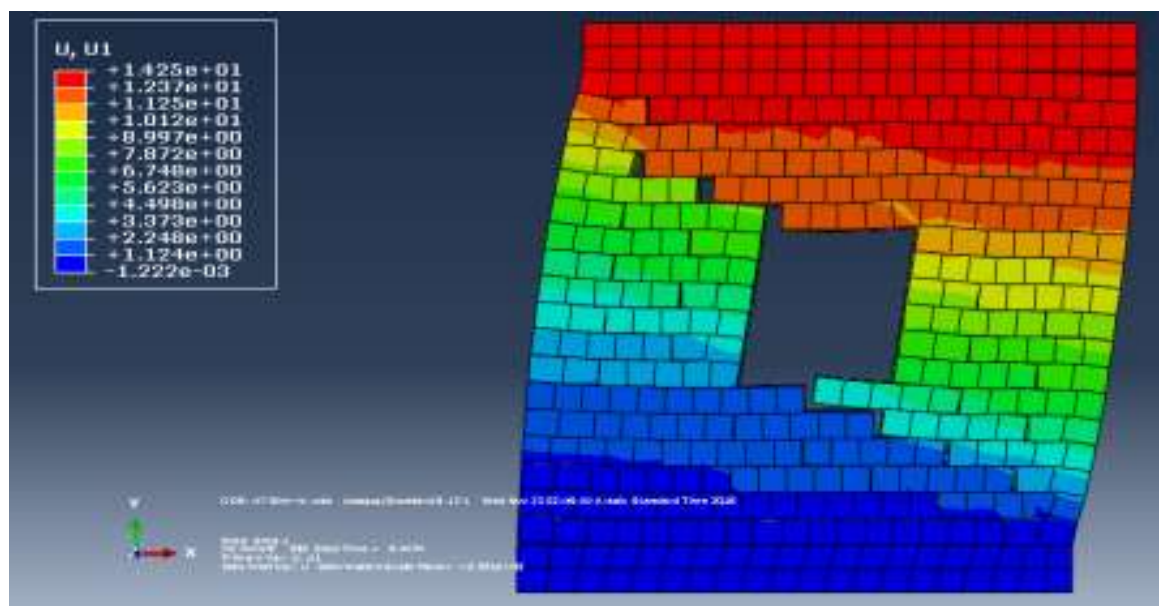

Fig. 10: Finite element modeling of Simplified micro-modeling by using ABAQUS

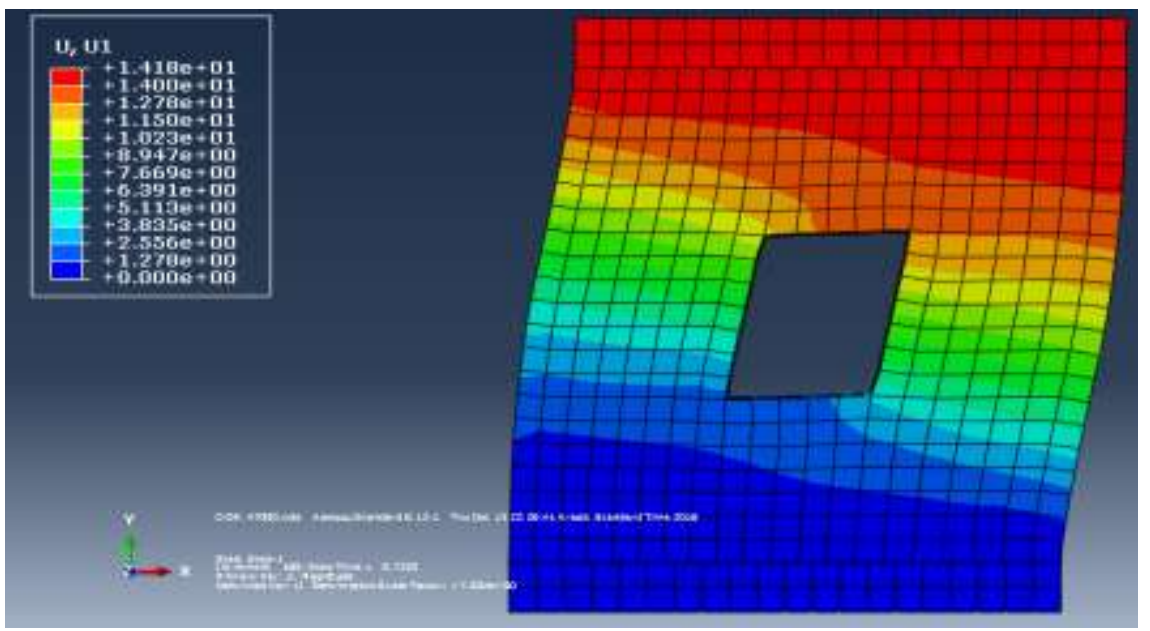

Fig. 11: Finite element modeling of Macro-modeling by using ABAQUS 


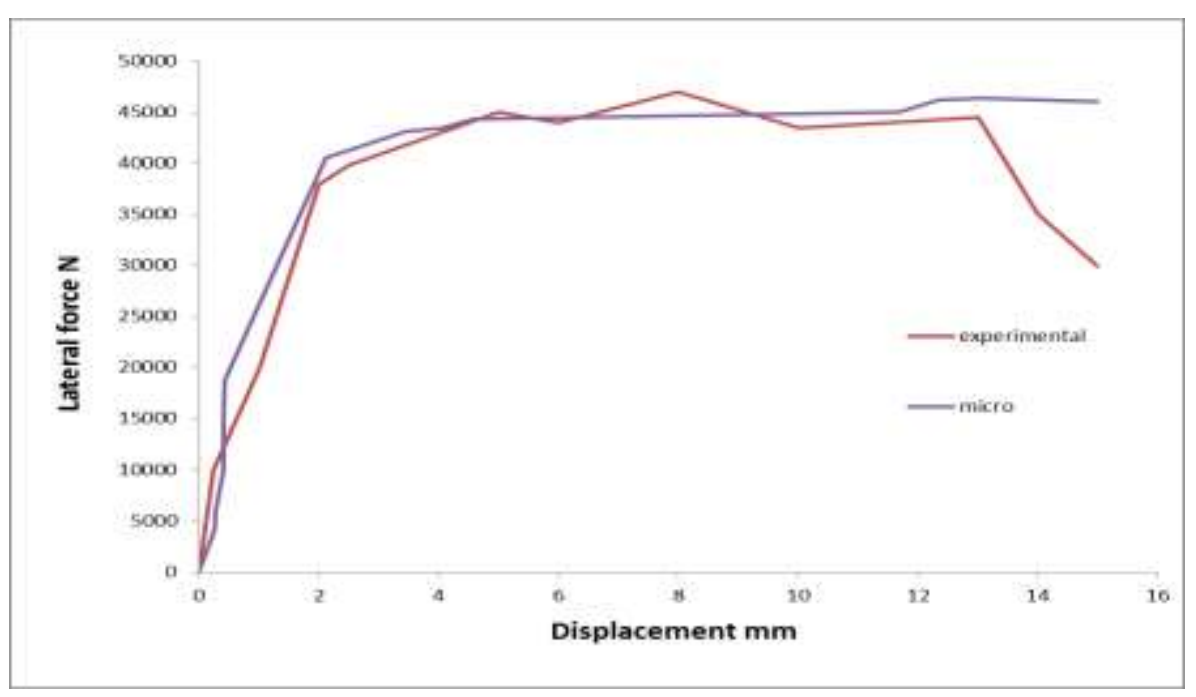

Fig. 12: Load- displacement of the masonry wall (Micro-modeling)

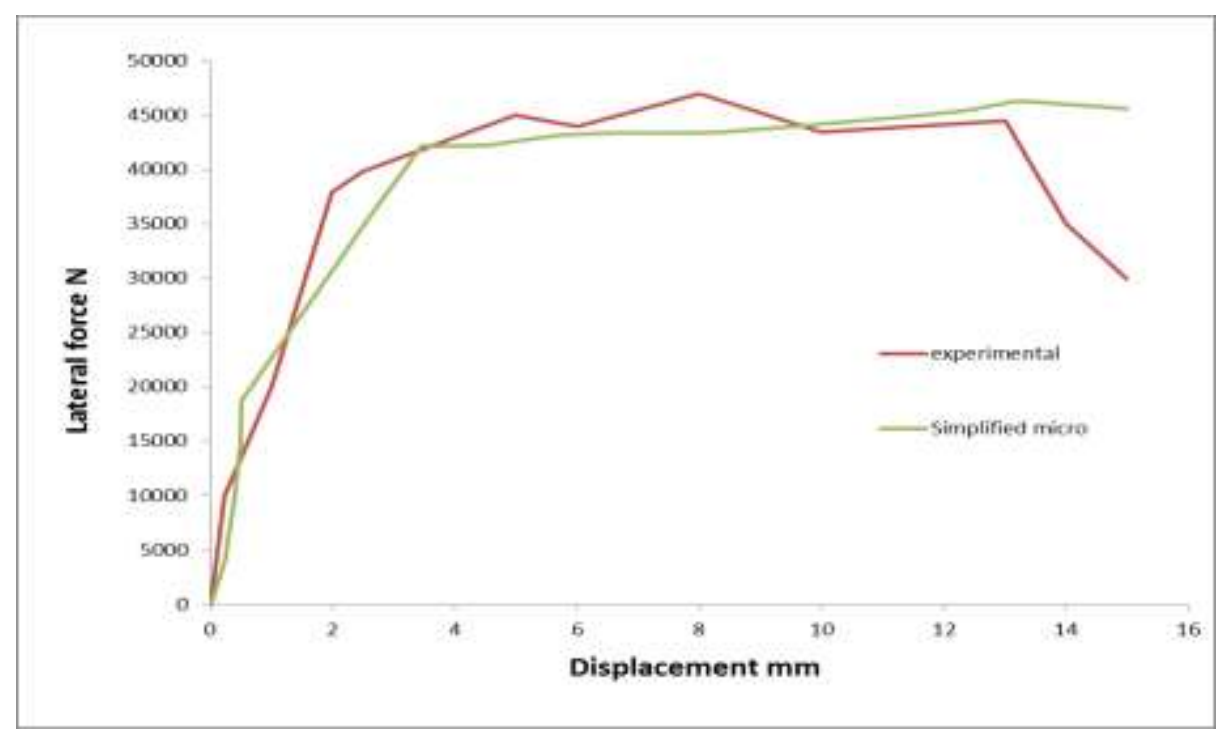

Fig. 13: Load- displacement of the masonry wall (Simplified micro-modeling)

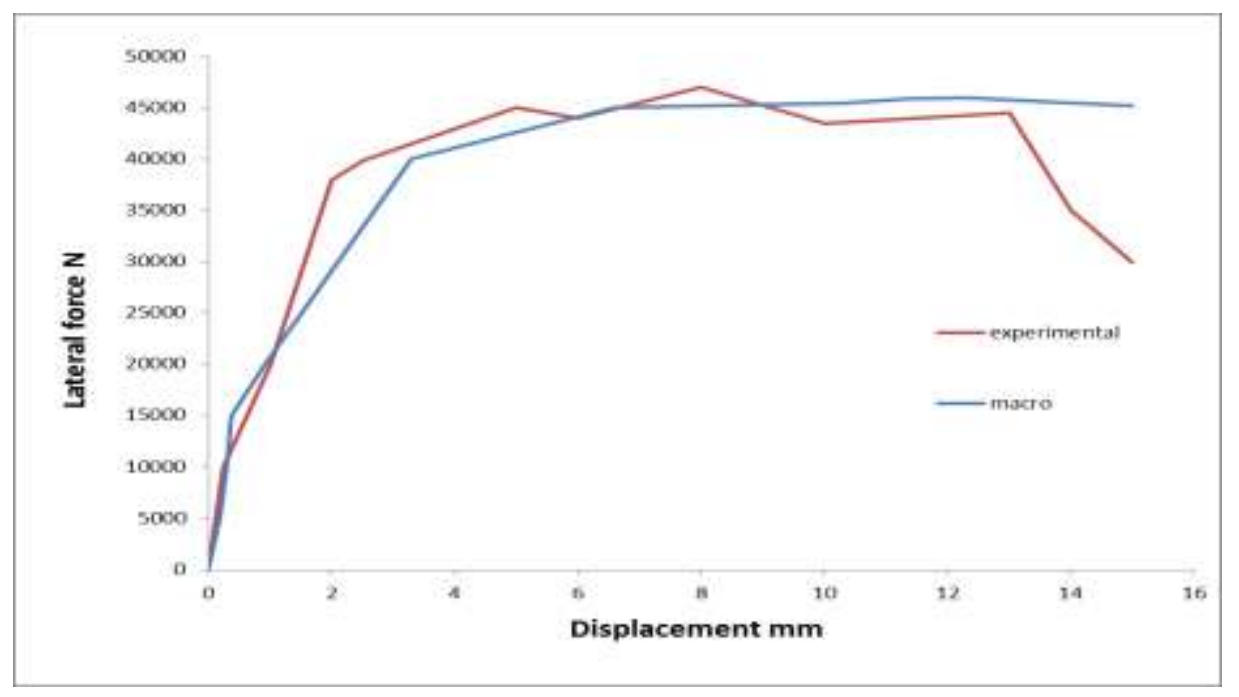

Fig. 14: Load- displacement of the masonry wall (Macro-modeling) 


\subsection{Results analysis of the masonry room:}

The masonry room is analysis for the seismic load includes of the dead and live load. The masonry room is subjected to PGA (0.592) as input ground motion to determine its seismic performance. The 3D finite element model of the single room used to simulation and experimental the experimental test as shown in Figure (5.5).the technic of macro modeling is adopted in this case study for easy modeling and being a large dimensional model. The maximum displacement found from finite element analysis is $55.51 \mathrm{~mm}$. while the maximum displacement found in the experimental investigation is $60.80 \mathrm{~mm}$. therefore The percentage error representation of finite element model is $8.7 \%$.The analysis results exhibit a good agreement of finite element analysis with previous experimental and numerical results for which amount of error is logical and acceptable as shown in Figure (15).

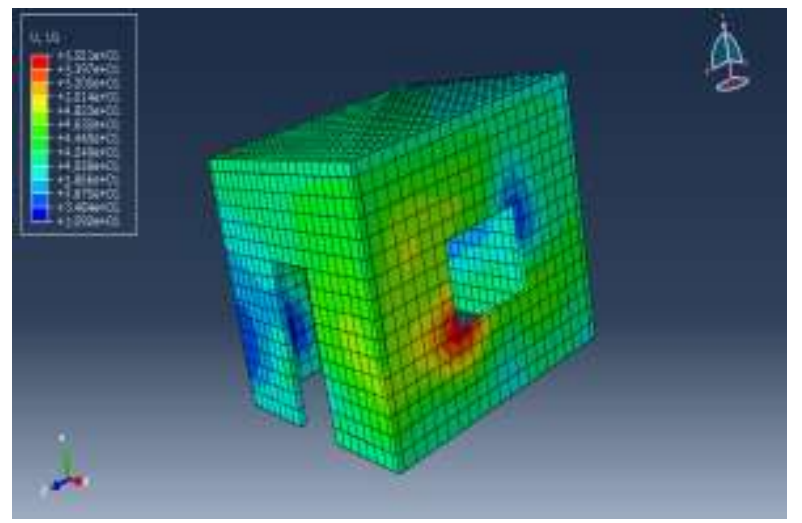

(a)

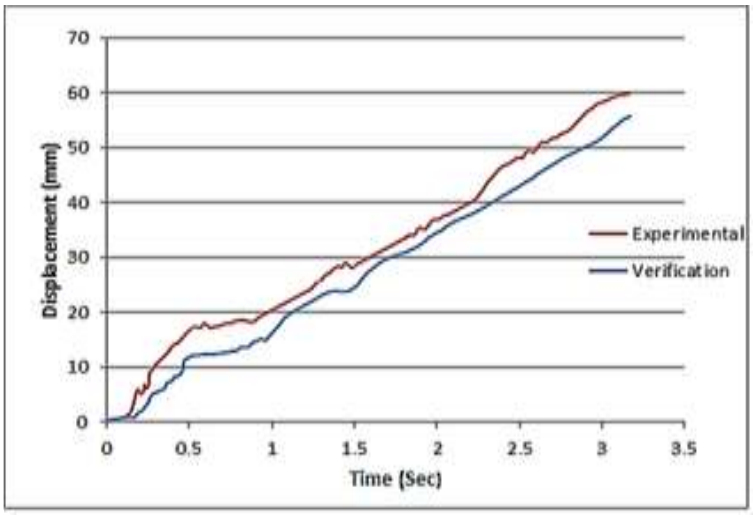

(b)

Fig. 15: a) Simulation of the of single room by using ABAQUS 6.13 program, b) The maximum displacement of experimental and 3D finite element model .

\section{Conclusion:}

This paper evaluates numerical representation using the finite element method of the program based on the representation techniques (micro, Simplified, macro modeling) of the masonry wall and evaluate the seismic performance of the masonry room using macro modeling.

1- Modeling techniques (micro, simplified micro and macro modeling) demonstrate high effective in representing the masonry wall in general and the nonlinear properties of materials in particular. Macro modeling is selected in this study because its save time and effort in addition to the no significant differences with the other strategies according to validation. The representation of masonry wall by brick element C3D8 has a great convergence with practical experiments under the effect of lateral loads and dynamic loads.

2- The case study for masonry wall analysis in two way applied lateral load and applied control displacement. The results confirmed the reliability of the representation techniques using the ABAQUS software. There was a great approximation between the experimental results and the results of numerical analysis when applied the lateral load on the wall with its three techniques, $95.47 \%, 95 \%$ and $94.54 \%$ for micro, simplified and macro modeling respectively. Similarly, when applied control displacement on the wall with its three techniques, 98\%, 97\% and 96\% for micro, simplified and macro modeling respectively. This result confirms the success of the modeling process of the wall with its three techniques and the degree of convergence among them. It was found that micro modeling can be used to study cases in small scale models and may be used simplified micro modeling to simplify them. The use of macro modeling is preferred in large scale models to provide time and effort, and its result is reliable for its great approximation with micro modeling and simplified micro modeling.

3- The masonry room was modeled by using macro modeling where modeling efficiency was very effective for obtaining approximation results of numerical analysis under dynamic load with PGA $(0.592 \mathrm{~g})$ as input ground motion and the experimental results. When applied the dynamic load of the masonry room is represented in finite element method by using ABAQUS program and a dynamic load applied to the masonry room model showing a convergence of results $91 \%$. The maximum displacement found from finite element analysis is $55.51 \mathrm{~mm}$. while the maximum displacement found in the experimental investigation is $60.80 \mathrm{~mm}$.

\section{Recommendation for future studies:}

1-Simulation of multistory masonry buildings under dynamic loads.

2- Simulation of masonry building with shear wall under dynamic loads to explain effected the shear walls of the behavior of masonry building. 


\section{REFERENCES}

Abaqus Analysis User's Manual 1-5 , 2009. Dassault Systèmes Simulia Corp., Providence, RI, USA

Ahmad, S., R.A. Khan and H. Gupta, 2014. Seismic performance of a masonry heritage structure. International Journal of Engineering and Advanced Technology, 4(3).

Aldemir, A., 2010. A Simple Seismic Performance Assessment Technique for Unreinforced Brick Masonry Structures, Yüksek Lisans Tezi, İnşaat Müh. Bölümü, Orta Doğu Teknik Üniversitesi, Ankara (İngilizce).

Annecchiarico, M., F. Portioli and R. Landolfo, 2010, August. Micro and macro finite element modeling of brick masonry panels subject to lateral loadings. In Proc., COST C26 Action Final Conf, pp: 315-320.

Aref, A.J. and K.M. Dolatshahi, 2013. A three-dimensional cyclic meso-scale numerical procedure for simulation of unreinforced masonry structures. Computers \& Structures, 120: 9-23.

Bolhassani, M., A.A. Hamid, A.C. Lau and F. Moon, 2015. Simplified micro modeling of partially grouted masonry assemblages. Construction and Building Materials, 83: 159-173.

Chambers, J. and T. Kelly, 2004. Nonlinear dynamic analysis-the only option for irregular structures. In 13th World Conference on Earthquake Engineering.

Costa, A.L.E.X.A.N.D.R.E., 2007. Experimental testing of lateral capacity of masonry piers. An application to seismic assessment of AAC masonry buildings. Universitat degli Studi di Pavia.

Daniel, A.J. and R.N. Dubey, 2014. Finite element simulation of brick masonry building under shock loading. Tenth U.S. National Conference on Earthquake Engineering Frontiers of Earthquake Engineering, 2125 .

Lourenço, P.J.B.B., 1997. Computational strategies for masonry structures. Ph.D. Thesis, Delft University, The Netherlands.

Srisanthi, V.G., L. Keshav, P.P. Kumar and T. Jayakumar, 2014. Finite Element and Experimental Analysis of 3D Masonry Compressed Stabilised Earth Block and Brick Building Models against Earthquake Forces. Periodica Polytechnica. Civil Engineering, 58(3): 255. 